\title{
Wordsearch, an Educational Game in Language Learning
}

\author{
S. Goumas, G. Terzopoulos, D. Tsompanoudi* and A. Iliopoulou \\ International Hellenic University - Management Science \& Technology Department, Kavala, Greece
}

Received 17 December 2019; Accepted 23 February 2020

\begin{abstract}
In recent years, digital games have taken an important place in the lives of children. Through play, children acquire digital literacy informally, even before they go to school. Games can also be used as a language learning tool nowadays. In this paper we propose a digital educational game, Wordsearch, for learning a foreign language vocabulary. In order to evaluate the game and to test its effectiveness in learning vocabulary, Wordsearch was evaluated by 11 students. Results show that the user interface of the application is simple and easy to use, and that the proposed Wordsearch Puzzle is likely to help long term vocabulary recall, while it makes learning fun by creating internal motivation to the students.
\end{abstract}

Keywords: education, game, language learning.

\section{Introduction}

One of the most important problems in the educational process is to provide students with sufficient and constant motivation, in order to engage in learning and to create the appropriate environment that will attract their interest. This is becoming increasingly difficult as young people today have sufficient Information Communication and Technology (ICT) skills, and they have already developed ways of learning influenced by these skills. Educators need to apply different approaches, using ICT, geared towards a learner-centered way of teaching. Educational digital games are also moving in this direction.

In [1], play is defined as "the activity that requires participation, competition with ourselves and/or opponents, in order to achieve specific goals, following certain rules". A broad definition of digital gaming defines it as the interaction of one or more players with the multimedia elements of an application, in order to achieve specific goals [2]. Users that achieve specific goals, earn points, change levels or even get a better position in the table that records the best performance scores. Educational digital games are created using game technology but for educational purposes, and they have certain content aimed at achieving specific learning goals [3].

In recent years, the integration of technology and the logic of games into the educational process, is referred with the term gamification. Gamification is the process by which all of the fun and entertaining elements of a game are reproduced in real-world situations or in productive activities [4]. One such productive activity is learning. According to [5], gamification uses game metaphors, elements and ideas, in order to create the right motivations and increase the attention and dedication of those involved, by cultivating desired behaviors. In another definition [6], gamification is the integration of game elements and logic, into non-game activities.

The educational process has many similarities with a welldesigned digital educational game. In both of them,

*E-mail address: despinats@uom.edu.gr

ISSN: 1791-2377 @ 2020 School of Science, HHU. All rights reserved.

doi:10.25103/iestr.131.07 participants' actions focus on achieving specific goals in the presence of obstacles [7]. It is also important for the players or students to progress accordingly in both cases, as their smooth transition to the next stages, depends on it. However, in the learning process, collaboration among students serves as added value for learning outcomes, whereas in digital games, competition is the key element that helps the participants to evolve. According to [8], children who are keen on digital media, such as video games, will be familiar as adults at risk and challenge and will use their imagination as useful tools in their work.

One of the most important benefits of using gamification in the educational process is providing sufficient and continuous motivation to the students. Student motivation may be due to both external and internal motivation. External motivations are not related to the subject of learning, such as parenting or finding work or other material rewards and are less powerful, thus, they motivate students for a shorter period. On the other hand, internal motives push students into an action that is an end in itself. Students are motivated internally, when engaging in challenging activities that trigger their curiosity $[9,10]$.

The purpose of this study is to create a digital educational game called Wordsearch, which will be part of the educational process and will assist in learning the vocabulary of a foreign language. The rest of this study is organized as follows: In Section 2, uses of digital technology in language learning are presented. Section 3 depicts the educational value of digital games in language learning, while Section 4 presents the algorithm used in the proposed Wordsearch game. Results from the pilot study regarding the use of the Wordsearch game by students are provided in Section 5. Finally, Section 6 presents the conclusions of the study and provides future research directions.

\section{Digital Technology in language learning}

Technology, when used correctly, can create a pleasant environment that simulates reality in order to effectively 
achieve language learning whether it is a native language or a foreign language. It allows students to develop skills outside the confines of the physical classroom, and as many researchers argue, can help students develop linguistic and cultural identities through different social and cultural environments, by interacting actively. Technology can also provide students with unlimited access to a variety of resources and information.

Today's generation is perhaps one of the first to have become accustomed to using computers, mobile phones and digital technology in general, from an early age. This continuous contact with technology, has significantly influenced the way we think and learn, since our experiences change the way the human brain is structured. It is therefore more urgent than ever, to change the way of teaching, by drawing closer to the way young people process and absorb information today. Digital games have a lot to offer in this direction.

There are at least 10 major differences between today's generation of young people and their predecessors, regarding the way they have been shaped by the widespread use of digital technology [11]:

- They have learned to live and think faster, by processing information much faster than previous generations.

- They process information parallely, not linearly. A common example is the ability of a young person today to talk on the phone while reading messages on a computer.

- They process information by random access rather than serial, using pattern recognition methods.

- Image is dominant in motivating them and keeping them interested, while text plays a secondary role.

- They work networked and in communities and this also affects the way they try to solve problems.

- They are more active than passive.

- They seek immediate feedback and they lack of patience.

- They can live more easily in fantasy worlds.

- They deal with the problems of life in the same way they handle the problems they solve in a digital game.

- Naturally, they are very familiar with the technology compared to all generations before them.

The story of the incorporation of technology into language learning begins with the use of the projector and continues with the audio-learning media in which the student was asked to repeat words or even phrases [12]. However, since the 1970 s, this method has produced very poor results, with the teaching of foreign languages in the 1980s and 1990s turning to the use of environments that fostered communication in authentic real-world environments. This trend coincided with the coming of the World Wide Web, which also expanded the field of knowledge and information of users regarding new technologies.

In the 1990s, the use of computers in foreign languages became more student-centered, influenced by sociological and cognitive theories aimed at teaching in authentic learning environments. This has opened the way for the use of $\mathrm{Web}$ 2.0 tools and foreign language learning, turning the student into an active participant and researcher. However, not even then the teaching focused on the psychological dimension of student mobilization [13]. The systematic use of modern educational digital games and gamification environments later took this dimension into account.

The World Wide Web has supported new forms of teaching based on distance learning such as:

- Blended learning, an approach to education that combines traditional face-to-face teaching and online educational materials.

- Asynchronous distance learning, where learning occurs when the teacher and students interact in different places and during different times.

- Synchronous distance learning, where students and the teacher communicate by distance, at the same time using technology such as chat rooms, skype or other environments.

The above methods are often combined not only with each other, but also with traditional teaching. Distance learning supports collaborative learning and redefines the role of the teacher and the students. Nowadays, the teacher is not the sole source of knowledge but acts more as a mentor, while students participate in shaping the content of teaching [14].

In order to facilitate distance learning, Learning Management System (LMS) environments have been used, which are online and facilitate access to rich educational material and its management, regardless of place and time [15]. Distance learning was originally used in adult education, although in recent years it has been combined with traditional teaching at young children during formal education. Environments such as Edmodo or Moodle, are being used to distribute audio-visual material to students, when they are no longer in the classroom, in order to help students understand the subject and to enrich their knowledge.

All of the above tools are also used effectively in language learning. In [16], the importance of computers in foreign language learning is presented and the study concludes that teachers should encourage students to discover and to use activities and games that improve their knowledge. Similarly, [17] supports that students should be guided to discover interesting and relevant linguistic topics online, while authors in [18] argue that activities related to new technologies can be beneficial in language comprehension and learning.

Research has shown that regardless of the age of learners, the learning benefits of using computers and the Internet in language learning are significant. A study [19] showed that using computers to teach English to adults has given them the opportunity to come into contact with the language in diverse environments beyond a typical classroom environment. It also promoted and fostered interaction between students and teachers.

In [20], the author studied 4 different classes, teaching different subjects, and came to the following conclusions regarding the use of ICT and especially the Internet in language skills learning:

- Teaching should be learner-centered so that students feel they have control over the learning process and its implementation.

- Activities should be formatted according to the electronic media.

- Students should participate in activities that express them in order to discover their identity.

The author, however, points out that students' expectations when using ICT in the learning process are 
particularly high, and therefore a potential failure in completing some tasks may cause students more negativity and criticism than in other cases.

From the above, we can conclude that despite the beneficial effect of computers on language learning, the use of ICT in education should follow some general guidelines and rules such as those proposed in [21]:

- The main linguistic features must be completely distinct and should provide opportunities for repetitions and modifications.

- Interaction between the learner and the computer should be supported, giving the student control over when to ask for help, modify and review the answers, and to repeat the study.

By following these guidelines, there is a greater chance of successful incorporation of ICT into the educational process, regarding language learning. However, the following restrictions should also be applied according to [19]:

- Deliberate efforts should be made to promote teamwork and interaction, otherwise the use of ICT may limit opportunities for meaningful interaction, a key element of language learning. Especially, in distance learning, the lack of sufficient interaction with the teacher and other students can lead to failure in creating a connected educational community in which the exchange of views and knowledge will lead to the development of new cognitive structures.

- Teachers need to be able to tailor curricula so that the use of ICT is not an end in itself but a tool to support learning goals.

- The ability of learners to have access to computers and the internet outside the classroom must be taken into account while designing the curricula, in order to ensure that students are treated equally. If some students don't have access to computers and the internet outside the classroom, it is advised to confine the use of ICT only in the traditional classroom environment.

- The cost of integrating ICT must be taken into account since software, hardware and maintenance require know-how and financial resources.

\section{Digital games in language learning}

Educational games are widely used in both native and foreign language learning. However, as reported in [22], there is an obvious difference between teaching a native language and a foreign language. Children learn their native language when exposed to the natural environment and refine it over time, while learning a foreign language occurs by standard methods and is usually associated with a more restricted environment such as class.

As authors in [23] report, for the past 40 years, language teaching has been constantly changing, shifting its goals from learning grammar and syntax, to enhancing communication skills. In this context, ICT in teaching of foreign languages is used not only to perform exercises aimed at examining grammar rules and text translation, but also to practice communication and meaningful approach of the content [24]. At the same time as stated in [25], everything that users study theoretically, could be particularly important, if they could apply it to a world of action-rich experiences [25]. Educational digital games seem to provide the ideal environment for this approach, as they offer a kind of language learning in protected environments [24].

The use of digital gaming in language learning, first occured in December 1971, when the Oregon Trail, one of the first digital simulation games, was used in Don Rawitsch's history lesson at Bryant Junior High School in Minneapolis, Minnesota [26]. However, it will still be several years before the use of digital games in the teaching of foreign languages is systematized. Since 2000, there are many interesting examples of using digital games for language learning.

In [27], the impact of communicative language games on learning English in elementary schools in Taiwan is studied. Research involving 150 teachers showed that these games help the educational process, but the teacher should take into account the differences in cognitive levels, the students' interests and requirements, and to adapt the game to this data, in order to maximize learning outcomes. Authors in [28] conducted a research in Turkey regarding the impact of computer games on learning a foreign language. The research was qualitative and was based on user experiences when playing internet-cafe games. The data was collected from semi-structured interviews and observations and showed positive impact of games, on language learning and especially on vocabulary acquisition.

Authors in [29] studied the impact of digital games on students' linguistic performance by comparing it with traditional teaching using ICT. The research was conducted in Taiwan, with 115 third grade students. Results showed positive impact of digital games on knowledge retrieval processes. Finally, authors in [30] studied vocabulary learning by using digital games in kindergarten. The study involved 67 local and immigrant children who took intensive vocabulary lessons using digital games for a period of 15 weeks, twice a week, for 15 minutes. The results of the study showed a positive effect of digital games and increased performance of children, in relation to the control group following traditional teaching.

According to [31], a video-game that teach a foreign language, must have the following elements:

- Interaction with other players, since this simulates how the younger generation has learned to solve problems.

- The socio-cognitive dimension, that relates to the use of language to complete specific tasks and achieve specific goals.

- Storytelling, as part of the video-game, since users tend to organize their experiences into short stories and in this way, basic language skills are acquired.

Another study [32] points out that an important element of a game that helps in language teaching, is the fast interaction with the player which is supported by voice recognition systems that are sufficiently tolerant to grammar and pronunciation errors by the user, so that the flow of the game is not easily interrupted. Another important element as noted in [33], is the challenges that the game presents, in order to create a "pleasantly stressful" environment. The latter element, according to [32], creates a pleasant mood and cultivates internal motivation in the learner by stimulating his interest.

However, a serious issue is the type of games that can be used in the educational process as well as their design. Following their experiments in [34], authors point out that 
when a game requires a high degree of interaction with the user, it causes a particularly high cognitive load and thereby reduces the benefits of understanding and memorizing of the linguistic object. Authors also observed that compared to students that played the game, students that just watched others playing, performed better in vocabulary tests than players. It is therefore important, to carefully select the appropriate game in teaching a foreign language. Finally, authors state, that it is more effective to organize the game so that it can be played in pairs, one of which will play and the other will watch the game, with rotating roles, so that each student can observe more carefully the elements of the game that require memorization and understanding.

Linking the situations that the player experiences in the game and in real life, seems to be a key factor in effective language learning. As reported in [35], in interactive environments, conversations that took place among the users, had no predetermined structure and content. This resulted in the improvement of users' language skills, since conversations were directly related to users' personal experiences and as a result, they could more easily recall elements of the language used in them.

Finally, another study [36] points out the importance of virtual reality games in language learning. Virtual reality seems to provide the ideal environment for language teaching as encourages the proper use of language by the users, enhances communication between users and collaboration, and at the same time offer a learner-centered environment where the learner can experiment through different situations that simulate reality.

\section{The algorithm of the Wordsearch game}

The Wordsearch game proposed in this study, always provides a solution even if it fails to integrate all the words. It also makes it possible to import vocabulary and corresponding definitions from a text file, so whenever a user reveals a word, its definition appears at the bottom section of the game. The Wordsearch game, incorporates basic elements of digital educational games, such as interactivity, and immediate feedback. The environment of the Wordsearch game is depicted in Fig. 1.

The design of the game follows the model proposed in [37] (Fig. 2).

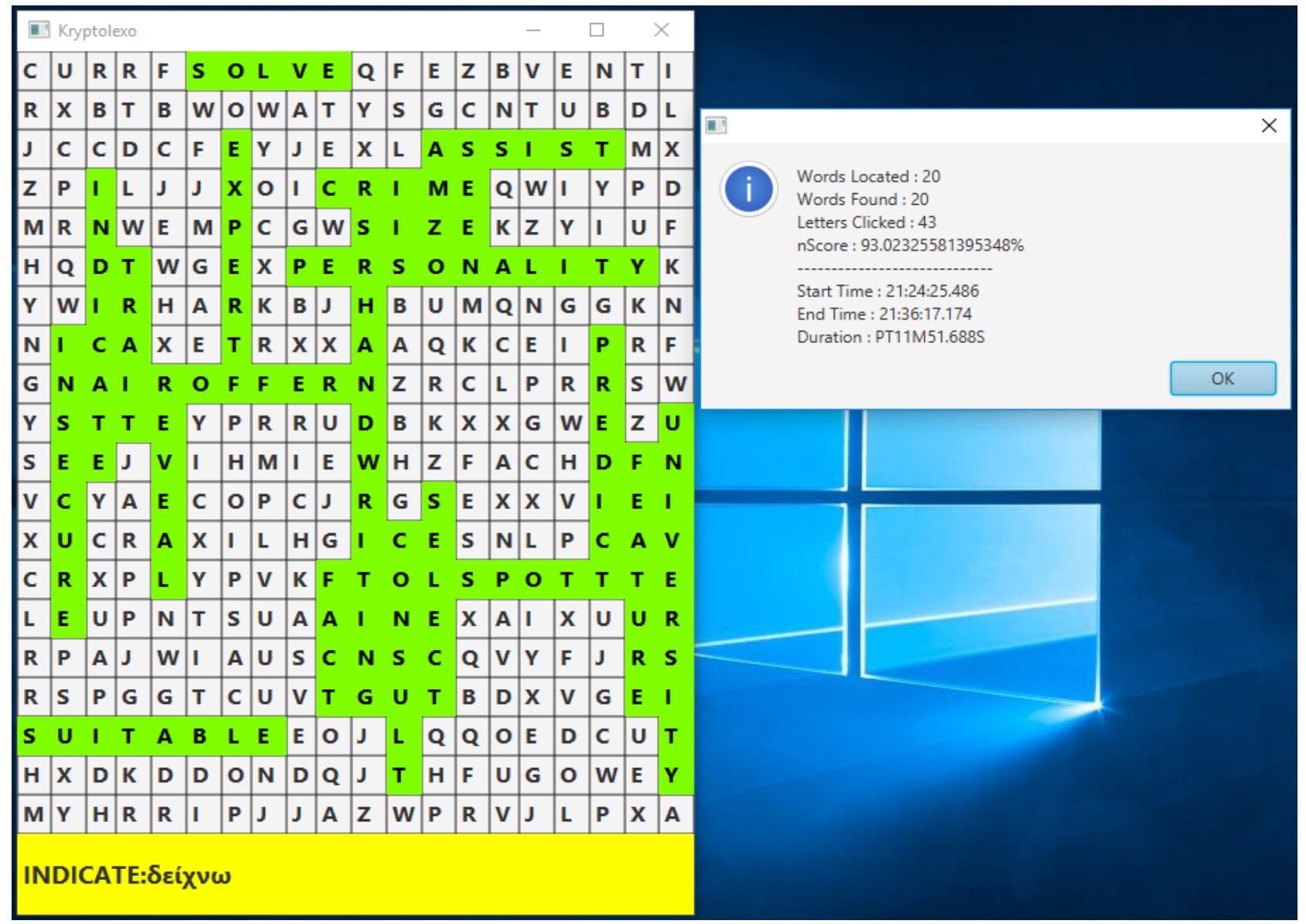

Fig. 1. The environment of the Wordsearch game containing 20 words, 8 vertical and 12 horizontal words

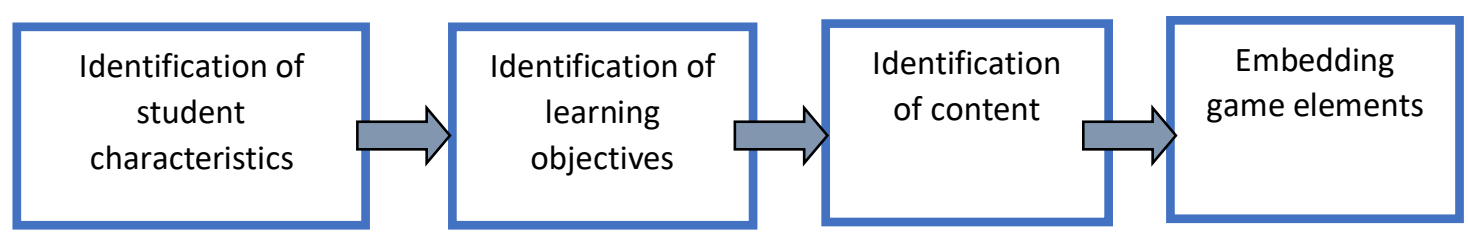

Fig. 2. Design model of the educational game 
The programming language chosen for the Wordsearch game, is Java, and in particular JavaFX, which provides the flexibility of working with a variety of platforms. JavaFX has built-in functions for advanced graphics, compatibility with different platforms, and is being constantly evolved.

The basic design of the Wordsearch game is summarized in the following steps:

1. Create a two-dimensional word table.

2. Input the word data from a text file, which contains both the words and the definitions of the words.

3. Place as many words as possible horizontally and vertically on the table.

4. Mark the words the user discovers, after selecting the first and last letter with the mouse. Along with this markup, the definition appears in a special textbox at the bottom of the user's screen.

During the development phase of the game, the following issues were taken into account:

- The words should be positioned horizontally and vertically so that they intersect in common letters.

- The address of each word specified by row and column should be such that it does not exceed the table's boundaries.

The proposed algorithm, positions a set of words $(\mathrm{k})$ and places them on a grid ( $\mathrm{n}$ by $\mathrm{m}$ ) grid. From the total words, some are placed horizontally (h) and the rest are placed vertically (v). The number of total words, vertical words, horizontal words, and the dimensions of the grid, are defined in the game's settings file. The algorithm places at most one horizontal word in each row and at most one vertical word in a column. Each horizontal word is placed on a randomly selected row. If the number of horizontal words is greater than the available rows then, an error message is displayed. Therefore, to place $\mathrm{h}$ horizontal words, $\mathrm{h}$ actions are needed.

Vertical words are placed after horizontal words are placed, and their letters must be placed either in empty cells or in cells where their letters intersect with the horizontally placed words. It is obvious that while each horizontal word is placed on the 1st attempt, a vertical word may fail to be placed on the 1st attempt. The number of maximum attempts (p) before excluding the word out of the game is specified in the parameter file (Settings) of the application. Thus, for every vertical word it may take a lot of effort to include it in the grid, and since there are $\mathrm{v}$ vertical words in total, all the vertical words will need $\mathrm{v}^{*} \mathrm{p}$ actions. Taking the actions needed for the horizontal words, the number of actions $(\mathrm{O})$ needed to place all words, is given by the following formula (1):

$\mathrm{O}=\mathrm{h}+\mathrm{v} * \mathrm{p}$

For example, in order to place 15 words ( 8 of them horizontally and the rest 7 vertically), on a 20 by 20 dimensional table, with the maximum number of attempts set to 100 , the actions needed at most, are:

$\mathrm{C}=8+7 * 100=708$

\section{Testing and pilot study}

The development of the algorithm and the implementation of the Wordsearch game, was followed by a test (A-Test) by the author, in order to check the correct operation of the game in both normal and extreme conditions, so that errors in the code could be corrected before the game reached the end-users. The game was tested for different vocabularies, with different number of words each time and with different word-lengths, as well as different number of vertical and horizontal words.

According to the proposed algorithm, the game fails to be created, displaying relevant messages in the following cases

- When one of the dimensions of the grid in the game is smaller than the longest word-length of a potential word.

- When the sum of the vertical and horizontal words to be placed in the grid, is higher than the number of words, present in the word file.

- When the number of horizontal words to be placed exceeds the number of lines in the grid or the number of vertical words to be placed exceeds the number of columns.

The above cases were checked by the author in the A-Test and it was verified that the appropriate error messages were displaced. After the initial testing, the game was evaluated by end-users (B-Test) regarding the functionality at the basic level and the user interface. In this case, B-Test aims to draw qualitative rather than quantitative conclusions. Qualitative research is not based on statistical methods and arithmetical data, in order to generalize conclusions, but enlightens the researcher and helps him understand and interpret the facts so that he can find their extensions to similar situations [38]. As stated in [39], in qualitative research the participant can be observed during the study or he can be interviewed with openended questions. The main characteristic of qualitative research is its inductive nature, as the researcher does not seek to verify a particular theory but, starting from a baseline analysis, attempts to formulate new theories and conclusions. Following the above methodology the current study covered both types of qualitative research. Users at first were observed during playing the game Wordsearch. After playing the game, a discussion followed by asking open-ended questions by the researcher.

Interviewing as a method of gathering information in a research, moves towards knowledge creation through human interaction and dialogue, while requiring participants to express their own interpretation of the world and events. Therefore, an interview is not just a collection of information about the events being examined, but an integral part of events and life, according to [40]. Thus, while observing participants provides clues to their behavior, the interview is the one that gives meaning to their behavior and can interpret their actions [41].

In the B-Test, a 20-word vocabulary-based Wordsearch game was created, and 11 students, 6 boys, and 5 girls in the age group of 12 to 15 years were asked to find words within the game. The length of the words varied from 4 to 14 letters. Words were given to students on a sheet of paper without interpretations. Each student played the game three times in a row, with the same vocabulary, but the words were placed in a different order each time.

The observation of the students revealed the following:

- Students enjoyed the game with pleasure and dedication. 
- Although there was no time limit, students were trying to find the words quickly, which became apparent in the second and third attempt. It was observed that students were competing with their past performance and therefore the game contained the element of challenge.

- At no stage did the students ask any questions about the rules of the game.

Thus, the following conclusions can be drawn from the above observations:

- As shown by the pleasure of the students during the game, the Wordsearch game, created internal motivation for the students through their involvement in the process. Internal motivation is also demonstrated by the challenge of making them perform better in each attempt.

- The Wordsearch game proved to have an easy to use environment.

In all cases, following the observation of the behavior of the players, an interview with open-ended questions was performed regarding the following matters:

- If learning the words with the Wordsearch game was more enjoyable and fun.

- If the game was easy to use.

- If learning the words within the game made it easier for students to recall and use new words.

- If the game environment was attractive.

- If students would like more impressive graphics.

- What other elements do students thought that would be necessary to be included in the game.

Students' interviews provided the following insights:

- All students agreed that learning the vocabulary using the Wordsearch game, is more enjoyable than the traditional way of learning. A 12-year-old girl commented that "Not long after the game started, I had forgotten that it was a word exercise".

- Regarding the question whether the game is easy to use, all students agreed that it seemed easy to them. The same conclusions were drawn from the observation of students while they were playing.

- When asked if they thought they could recall the words and use them in the future, most students responded that they did not know. Specifically, 6 out of 11 students responded that they did not know and would only comment if they were asked to use the words verbally or in writing after some time, 3 of them replied that they thought they would be able to remember and use the words more easily in the future, while two 15 year-old students, noted that they thought they would be more likely to recall words if there was audio material with pronunciation of the words in the game. This observation moves in the direction of the proposed improvements of the present work and the elements that are likely to be incorporated into the game in future releases.

- Regarding questions related to whether the game environment is attractive, interviewers tended to compare the Wordsearch game with other graphicrich interactive games and responded negatively. These answers were to be expected, given that most of the games nowadays, include 3D graphics and animations.

- Finally, when students were asked to suggest improvements, they said they would prefer Wordsearch to be "like little cubes on top of each other" (three-dimensional), to have some music background when discovering a word, and that the interpretation of the word being accompanied by its pronunciation with related audio material. They would also like some examples of word usage in sentences. In one case, a 15-year-old boy suggested adding an avatar to the game, which could act as an assistant to the player and reward him when he discovered the words.

Although Wordsearch is a static game, it is obvious that the above elements can enrich it and emphasize its interactive character, contributing to user engagement and internal mobilization.

\section{Conclusions}

Nowadays, digital games have been integrated into the educational process, and in particular, in foreign language learning, with positive results. When their design follows a development framework that prioritizes student characteristics and learning objectives, and when they include interesting graphics, they can improve student interaction with each other, by providing rich sources of information and creating a reality-like environment.

By following the basic principles of educational digital games, the Wordsearch game presented in this study, was created to facilitate the learning of a foreign language vocabulary. The game helps with word memorization, provides internal learning motivation and can be effective in recalling words after a long time.

The Wordsearch game can be further improved aesthetically by adding 3D animated graphics. Additionally, by adding multimedia elements, such as audio, so that students can hear the pronunciation of the words, or by adding an avatar who can direct students in finding the right solutions, the game can be more effective in learning. These particular improvements will be an interesting addition to the Wordsearch game, in future releases, so that the game can assist in language learning more efficiently.

This is an Open Access article distributed under the terms of the Creative Commons Attribution License

\section{References}

[1] L. Aghlara and N. H. Tamjid. The effect of digital games on Iranian children's vocabulary retention in foreign language acquisition. Procedia-Social and Behavioral Sciences, 29, p. 552-560 (2011).
[2] N. M. Sin, O. Talib, T. P. Norishah, A. A. Ishak and R. Baki. Male students and digital game: Reason, motivation and feeling. 
International Journal of Information and Education Technology, 4(1), 6 (2014)

[3] V. Nagalingam and R. Ibrahim. User experience of educational games: a review of the elements. Procedia Computer Science, 72, p. 423-433 (2015).

[4] C. Yu-Kai. Gamification and behavioral Design. Retrieved 12 December 2019 from https://yukaichou.com/gamificationexamples/octalysis-complete-gamification-framework/ (2018).

[5] A. Marczewski. What's the difference between Gamification and Serious Games. Retrieved 12 December 2019 from https://ubm.io/2OYkDKw (2018).

[6] G. Kiryakova, N. Angelova and L. Yordanova. Gamification in education. Proceedings of 9th International Balkan Education and Science Conference, (2014).

[7] I. Glover. Play as you learn: gamification as a technique for motivating learners. In EdMedia: World Conference on Educational Media and Technology. Association for the Advancement of Computing in Education (AACE), p. 1999-2008 (2013).

[8] J. C. Beck and M. Wade. Got Game: How a New Generation of Gamers Is Re-shaping Business Forever, First Printing (2004).

[9] M. R. Lepper and M. Hodell. Intrinsic motivation in the classroom. Research on motivation in education, 3, p. 73-105 (1989).

[10] J. C. Hong, C. L. Cheng, M. Y. Hwang, C. K. Lee and H. Y. Chang. Assessing the educational values of digital games. Journal of Computer Assisted Learning, 25(5), p. 423-437 (2009).

[11] M. Prensky. The motivation of gameplay: The real twenty-first century learning revolution. On the horizon, 10(1), p. 5-11 (2002).

[12] M. Warschauer and C. Meskill. Technology and second language teaching. Handbook of undergraduate second language education, 15 , p. 303-318 (2000).

[13] J. F. F. Flores. Using gamification to enhance second language learning. Digital Education Review, (27), p. 32-54 (2015).

[14] J. M. Galusha. Barriers to learning in distance education (1998).

[15] E. W. Black, D. Beck, K. Dawson, S. Jinks and M. DiPietro. Considering implementation and use in the adoption of an LMS in online and blended learning environments. TechTrends, 51(2), p. 3553 (2007).

[16] J. Harmer. How to teach English. England: Pearson, (2007).

[17] L. Cameron. Teaching languages to young learners. Cambridge: Cambridge University Press, (2009).

[18] D. H. Clements and J. Sarama. Strip mining for gold; research and policy in educational technology-a response to fool's gold. Educational Technology Review, 11(1), p. 7-69 (2003).

[19] CAELA Network: Resources: CAELA Network Briefs: Uses of Technology in the Instruction of Adult English Language Learners. (n.d.). Retrieved 12 December 2019 from http://www.cal.org/caelanetwork/resources/usesoftechnology.html

[20] M. Warschauer. On-line learning in second language classrooms: An ethnographic study. Network-based language teaching: Concepts and practice, p. 41-58 (2000)

[21] C. A. Chapelle. Technology and Second Language Learning Acquisition. Annual Review of Applied Linguistics, 27. https://doi.org/10.1017/S0267190508070050, (2007).
[22] B. Hart and T. R. Risley. Meaningful differences in the everyday experience of young American children. Paul H Brookes Publishing (1995).

[23] M. Warschauer and R. Kern (Eds.). Network-based language teaching: Concepts and practice. Cambridge university press (2000).

[24] B. H. Sørensen and B. Meyer. Serious Games in language learning and teaching - A theoretical perspective. In DiGRA Conference (2007).

[25] J. P. Gee. Pleasure, learning, video games, and life: The projective stance. E-Learning and Digital Media, 2(3), p. 211-223 (2005).

[26] Oregon Trail Game Played for the First Time. Retrieved 12 December 2019 from http://portland.daveknows.org/2011/12/03/december-3-1971oregon-trail-game-played-for-the-first-time/, (2011).

[27] Y. H. Wang. Using communicative language games in teaching and learning English in Taiwanese primary schools. Journal of Engineering Technology and Education, 7(1), p. 126-142, (2010).

[28] Y. Turgut and P. Irgin. Young learners' language learning via computer games. Procedia-Social and Behavioral Sciences, 1(1), $\mathrm{p}$. 760-764, (2009).

[29] T. Y. Chuang and W. F. Chen. Effect of Digital Games on Children's Cognitive Achievement. Journal of Multimedia, 2(5) (2007).

[30] E. Segers and L. Verhoeven. Effects of vocabulary training by computer in kindergarten. Journal of Computer Assisted Learning, 19(4), p. 557-566 (2003).

[31] C. I. Hitosugi, M. Schmidt and K. Hayashi. Digital game-based learning (DGBL) in the L2 classroom: The impact of the UN's offthe-shelf videogame, Food Force, on learner affect and vocabulary retention. CALICO Journal, 31(1), p. 19-39 (2014).

[32] W. L. Johnson, H. H. Vilhjálmsson and S. Marsella. Serious games for language learning: How much game, how much AI?. In AIED, 125(1), p. 306-313 (2005).

[33] J. P. Gee. What video games have to teach us about learning and literacy. Computers in Entertainment (CIE), 1(1) (2003).

[34] J. DeHaan, W. M. Reed and K. Kuwanda. The effect of interactivity with a music video game on second language vocabulary recall Language Learning \& Technology, 14(2), p. $74-94$ (2010).

[35] R. Young. Computer-assisted language learning conversations: Negotiating an outcome. Calico Journal, p. 65-83 (1988).

[36] K. Schwienhorst. Why virtual, why environments? Implementing virtual reality concepts in computer-assisted language learning. Simulation \& Gaming, 33(2), p. 196-209 (2002).

[37] Kiryakova, G., Angelova, N., \& Yordanova, L. (2014). Gamification in education. Proceedings of 9th International Balkan Education and Science Conference, 2014.

[38] M. C. Hoepfl. Choosing qualitative research: A primer for technology education researchers, 9(1), (1997).

[39] R. Bogdan and S. K. Biklen. Qualitative research for education. Boston, MA: Allyn \& Bacon (1997).

[40] L. Cohen, L. Manion and K. Morrison. Research methods in education. Routledge (2002).

[41] I. Seidman. Interviewing as Qualitative Research: A Guide for Researchers in Education and the Social Sciences. Teachers College Press (2006). 